of nose to centres of pupil is, as a rule, from $\frac{1}{16}$ to $\frac{1}{8}$ of an inch, seldom is the difference beyond $\frac{1}{8}$ inch. But if the difference is $\frac{1}{8}$, and lenses are mounted in the ordinary way, we have a decentering of both lenses to the right or left, as the case may be, of $\frac{1}{T E}$ inch. If the greater distance from centre of nose to centre of pupil is on the left side, then we have, if our lenses are convex, a prism also for left eye, with base in, and for right eye a prism with base out. If they are concave, the reverse would be true. Persons familiar with this subject know how important this would be in lenses of medium to high power.

This brings in a new element not heretofore considered in the grinding and mounting of spectacle lenses. In presence of the facts stated, we are under obligations to take cognizance of the same, and in every case satisfy ourselves whether the centre of the nose is in the exact centre between the two pupils. It becomes necessary to make the centre of the nose the starting point for measurement. I have constructed a simple little instrument which answers admirably for measuring either way from the centre, as follows: Take a piece of wood 6 inches long, 1 inch wide, $\frac{1}{8}$ inch thick, draw a straight mark across its exact centre, and then one on either side just 1 inch from this, with the blade of a knife. Ontside of the two outer lines mark accurately $\frac{1}{16}$ inch marks until you have reached a $\frac{1}{2}$ inch beyond, making marks near the edge. These marks may all be colored with ink. Now cut out a concave notch in the centre of the marked edge, about $\frac{5}{8}$ inch wide and $\frac{1}{4}$ inch deep. This notch will fit down over the nose, when you must see that the centre line of your measare is exactly over centre line of nose. Now read off to right and left 1 inch and so many sixteenths. Of course any one's ingenuity will suggest how to neatly make this measure. You may construct one much easier by taking a common thin-edged, wooden measuring rule, and make the notch in it at any inch mark; you have your inches and sixteenths on either side already provided. Our instrument makers, no doubt, could construct something very neat for these measurements, with a handle just above the centre, a concave portion just beneath this to rest on nose, and arms extending out to right and left, with proper intervals marked thereon. This might also have little slides with points to stop in front of pupils.

But the measures being taken, what about the mounting of glasses? Surely they must be so set in frames that the optical centre of lens comes before the centre of pupil, no matter where the centre of eye wire is. The frames cannot be constructed longer on one side than the other, else they would not balance, but the lenses must be decentred in grinding to correspond with measurements. This will necessitate a new form of prescription blank, first giving the total measurement between pupils, and then the measurement of each side.

I have examined a large number of faces since the fact herein mentioned came to my knowledge, some months since, and I find it quite the exception for the nose to be centrally situated. I made the discovery on my own face, in which case the right pupil is $1 \frac{1}{8}$ inches from centre of nose, and left $1 \frac{1}{4}$ inches.

The Woman's Medical College of Minneapolis has been incorporated according to law.

\section{MODERN MEDICAMENT.}

BY C. B. MEDING, M.I., OF NEW YORK CITY.

Of the physician's duty toward his patient much has been set forth by the press, medical, religious, and secular. It remains for our body to present and enlarge upon as well as to impress one another with the importance of our duty toward ourselves. Though often lost sight of, it is still of first magnitude, morally, professionally, and financially. However strongly it may be held that professional life has in consciousness its own reward, however often it may be reiterated that worldliness is no part of our creed, the truth remains that, in common with the rest of humanity, we must live and must fight for life. We have enemies, we have opposition and competition, antagonistic factors that will of necessity be victors or vanquished.

Not a few of us here present have found that the voyage is not over an altogether smooth sea, is not free from storm and hurricane, not safe from shoal and rocky coast line, and while we pilot fellow craft through the billows of accident, while we gear the engines of stranger ships, if we would be thorough seamen we must steer our own bark aright, weathering successfully the tempests we are sure to meet.

The old has no rights over the new, whether in medicine, theology, philosophy, or astronomy; its principles must change with the times, its tenets must bear reform. To the survival of the fittest there is no exception, and while we accept for diagnostic purposes new etiology, new methods of examination and deduction, we must perforce take hold on new treatment.

I am afraid that many who are and ought to be opponents of homeopathy know little of the real therapeutics, much less of the principles of that school. I am afraid that outside of "similia similibus curantur" and "high dilution" little is known or cared. But a direct and successful opposition must be based on knowledge. If the system of medicine practiced by us is right, if it is worth study, attention, and continuation, it is also worthy of protection. If the opposers of it claim fallacies as against it, we as men should be prepared to maintain our position by a full refutation based on intelligible facts, and I am one steadfast believer and practitioner of the old school who has had the truth forced upon him that homeopathy is, under existing circumstances, his greatest enemy, that it has done and is doing more harm to all regular practitioners than any form of quackery; that it has made many semi-converts and at the same time has fostered ignorance and misapprehension; all this not because of superior efficiency from strength of basis or soundness of principle, but through pleasant dosage and a common sense plan of cheap and ready medication.

The age that cries for rapid transit, electric conveniences, automatic novelties, in a word, for everything that may lessen the friction of life; the age that demands comfort, ease, and luxury, in every bypath of its daily walk, will not accept vile concoctions even at the hand of learned men, nor will it long consider learned those who continue such medication, and the best purpose homeopathy can ever serve will be the teaching the abandonment of filthy compounds.

There is no reason why we should persist in prescribing nauseating drugs. The moral effect of such medicine may be useful in hospitals, purging them of 
simulating patients; the so-called "bum mixture" has its place, but alas it is most often prescribed in private practice to delicate patients. Let me recite a few facts and see if we can find causes for them.

It is a common occurrence to find parents choosing homeopathic treatment for their children, they remaining alopathic.

It is commonly said by intelligent persons: "Oh" yes, in severe cases I prefer the old school, but for simple ailments homeopathy will do."

It is not uncommon to find a homeopathic medieine book in the homes of old school people.

Few physicians have escaped the pleasant scene of a couple of half filled tumblers with the ever present saucer and spoon, in the nurseries of their patients.

We cannot, if reasonable men, ignore the homeopath, nor browbeat the laity with any satisfaction. We cannot sanely call all homeopaths fools. and decisions arrived at by the popular mind are the indicies of progress, and popular logic has its place. This being the case one cannot ask a people to more readily believe in the necessity of assofœdita and senna than that the thirty-third dilution of a single drop is stronger than the drop itself. Both are preposterous, but of two evils common sense chooses the pleasantest.

I do not consider it a difficult task to prove the falseness of homeopathy considered as an all providing and sufficient system. Any man can prove empiracy to be the only sure basis, but to prove worthlessness in anything but sin is impossible. Outside the more or less well defined circle of physiological effect on the average normal subject, we find individual idiocyncrasy a powerfully modifying factor. But the dose admits of common sense. We camnot deny two things; first, that with liquids the old school prescribes large vials and spoon doses while the homeopath gives small bottles and drop doses; in solids we lean toward few pills or capsules regardless of size. The homeopath gives small pills regardless of number. I ask you, both being possible, which is the most reasonable?

Two further factors worthy of consideration are the patent medicine and the drug store.

As regards the first I believe its success is due not to the gullibility of the public, for many purchasers are intelligent reasoners, but to three inherent and ever present merits, cheapness, pleasantness and safety. exactly the merits of homeopathy, precisely the merits, gentlemen, that recommend any purchasable artible. Cheap because they diagnose, explain, and treat for the same money; pleasant. Take any one of the successful remedies of the day and tell me, despite your opposition, are they not elegantly prepared? do they ever sour, mould, or precipitate? Are they ever unsightly? Is there any illegible writing to be read? Are they ever nauseating? Are they not always one bottle exactly like another of its kind? Safe, for obvious reasons. Is not the reverse often true of our preseriptions?

The drug store may be justly likened to a traitor in friendly garb. It is not the counter prescribing, nor yet the information culled from presciptions that effects the question, but the prices charged for drugs. Of this the most casual observers need neither explanation nor example other than their own experience. With some there may be a question as to where to draw the line of personal affairs. For my part I must admit that the vast majority of people belong to the great middle class, to whom success means simply a balanced ledger at each year's end, and to whom extortion is robbery. Every man has the right to do as he will with his own. "If I am not satisfied, you say, I may go elsewhere. True, but in the time of necessity I must pay, for I am compelled to have. A price based upon the sum of cost and profit is reasonable, but there is no honor nor fairness in the price based on man's necessity.

Many reputable physicians have taken to carrying with them a supply of simple drugs, believing that they are entitled to a share of the patient's money. It requires no deep reasoning to see that a man in humble circumstances cannot pay equally doctor and druggist, and that if the doctor must give credit while the druggist need not, the former is the loser. More than this, some physicians are to-day carrying a small stock of common medicines for office practice. This is a good thing, it will have a twofold effect. It will cause the city physician of the old school to become acquainted with the medicines he prescribes, will cause him to consider palatability, and patronize all efforts to afford a happier dosage; it will also compel the stores to sell at more reasonable prices. It is our duty to oppose all, who antagonize the hest interests of the highest profession and prosper homeopathy, charlatanism, and patent medicine.

The day is happily not far distant when the uneducated will be cut off from medical study; when State examinations will make low grade colleges impossibilities, but at present there are many good reasons why we confess so many sad writers and poor students. Incompatibility is now tanght to prevent poisomous or explosive compounds and for nothing more. It has been said that city physicians have least faith in the materia medica, country physicians most; true it is that the former never compound, seldom see and never taste their medicines, hence their fearful mixtures.

Now a few points along which to draw the lines of opposition. It is time for us to,

1. Combat the growing impression that old school means dosing.

2. Prove that alopathy does not mean extravagant drug bills.

3. Prove that we, too, can treat the emergency and are not altogether dependent on the drug store.

These three now truthful ideas may be banished successfully by following the physiology, chemistry, therapeutics, and common sense of the day. Let us,

1. Reduce four and six, and eight ounce vials to one, two and three ounce; and the dose from drachms to minums.

2 . Rednce the number of prescriptions, seeking simpler medication and less complication.

3. Use consentrated tinctures and extracts, compressed solids, and active principles.

4. Abolish decoctions, infusions, and crude drugs; cease ordering ounces of vehical to carry grains of medicament.

5. Carry carefully selected drugs. Dispense such medicines as may be conveniently handled, raising our profession to its old time usefulness. Such a course will,

1. Reduce the price. A druggist cannot charge the same for a two ounce as for a four ounce vial, even though the difference be only boiled water. It will

2. Abolish that large class of preparations of which 
our text-books say, "used mostly as vehicals." It will, loiter, tracing out old footsteps time has well nigh

3. Prove us consistent, for it is no more ridiculous obliterated? Dare you stand copying masters, proand blameworthy to attend a confinement without gress calls children? Is it not your duty to steer ergot, instruments, and antiseptics, than to enter. the this light-ship carefully, scientifically, reasonably, abode of sudden sickness at midnight armed with always mindful of the good, ever willing to discard simply paper and pencil.

There is an opinion abroad that the doctor has in nothing to do with cost, but my impression is that doctor from doceo means to teach, and the good teacher is interested in all that affects his pupil. He who is not a teacher is not a doctor, but a leech; of course it is for every man to choose his own professional title.

A druggist is no relation to a physician and he should be none. The percentage system is criminal extortion, and that man illy serves his patient who lays up treasures in a druggist's till. I believe that if every physician would buy his drugs, his own prescription blanks, segars, postage stamps, etc., it would be better for all hands.

It camnot be brought against such rulings that heroic treatment necessitates dosage, for nastiness and quantity are not synonymous with strength.

Again, why should we not seek the proper compounding of preparations? Why should pills be made in sixteenth century sizes and modes, if they are to be sold at nineteenth century prices? Why should not fresh parvules and pills and tablets be made by men who style themselves dispensing chemists, apothecaries and pharmacists?

Lastly, why cannot we turn against medicines famous most for their filthiness?

You ask where this line is to be drawn. Will not palatability lead to the elixer, would that be advisable? Such is the argument and objection of the extremist. It is not necessary to have the child cry for medicine. I do not desire adults to prefer drugs to food. Very far from my creed is it to claim that medicament must be nice or useless. Many times in the practice of every man will come the cases where taste and cost sink in the imminence of death, but in over two-thirds of our cases, petty ills, trifling disorders, and simple ailments comprise the trouble, and here we can show that the grand old school has not only age but also modern weapons for the warfare with disease.

The country physician laughs at the city man's medicine, yet he has learned better only by experience.

Is it true that the homeopath has better results with children than we do? Well, if it is true, the reason is not in any superior system, but in drops instead of drachms; in pellets instead of marbles.

You cannot read how to improve; there are no books, no colleges. Edinburgh, Glasgow, London, Heidleburg, and Vienna, all are fighting tooth and nail for the black draught and blue bolus. Improvement, progress, civilization, however, demand responsive souls. You cannot bribe the great time, it will onward and in its train humanity rises to higher levels.

The searing iron stopped many a hæmorrhage in the past, why not continue its use? Microbes were never molested until lately, why bother them now? Thousands of persons were operated without anæsthetics and survived, why so tender now?

Because the age demands, invention supplies, and discovery brings forth. We are working, studying, pressing forward and onward toward a brighter, higher end. Then can you lag behind? Dare you

the had? That they who navigate the etermally rolling sea may, seeing its brilliance, guard their craft aceordingly.

\section{INTLBATION IN DIPHTHERIA.}

Read before The Mitchell, Ind., District Medical Society, Dec., 17, 1891. BY P. RICHARD TAYLOR, M.1).

I will make a strictly clinical report of four cases of intubation, selected from a number during the recent endemic of diphtheria in Louisville, two of which were fatal, and two successful.

Case I.-Oct. 29th; I was called by Dr. Ernest. Yeager to intubate the larynx of Robt. W., æt. 7 years and 5 months. On examination I found diphtheritic patches on the tonsils and in the pharynx. In the larynx the mucous membrane was swollen and tumefied, but there was no false membrane. Respiration, 36 per minute; pulse 150 and thready; temperature $102 \frac{1}{2}$. He was in a semi-comatose condition and very much cyanosed. The intercostal spaces were depressed and did not rise with inspiration. The dyspnoea was distressing. A tube the size required for an eight year old child, was introduced into the trachea, which relieved the dyspnoea immediately. At the end of an hour, respiration was 22 ; pulse, 140. Quinine by inunction and iron internally were prescribed. Milk, six parts, whisky, one part, to be given alternately with beef extracts, were ordered for nourishment. A spray of peroxide of hydrogen was used every hour. The following morning, the temperature was $99 \frac{1}{2}$; pulse, 120 . I saw the child again on the sixth day, found the temperature normal; pulse 100. The tube was removed on the seventh day, the child making an uninterrupted recovery.

Case 2.-Nov. 2nd., I was called by Dr. Robert G. Fallis to intubate the larynx of Rose H., æt. 2 years and 8 months. Epon examination, I found diphtheritic membrane in the nares and pharynx, on the tonsils and tongue and in the larynx. The child had been sick but forty-eight hours; the temperature was 102 ; the pulse, 150 ; the dyspnoea excessive and progressing. A tube the size required for a child three years old was introduced into the larynx, relieving the dyspnoea immediately, and in ten minutes the child was asleep. Quinine by inunction, iron internally, were prescribed. A spray of sulphurous acid and water, equal parts, was ordered. Milk and whisky, alternately with beef extracts, were given as nourishment. On the morning of the second day, found the temperature 100; pulse, 130 . On the morning of the third day, temperature 101; pulse 140 ; face flushed; membrane yellow and breaking down. A spray of peroxide of hydrogen was ordered to be used every hour. On the morning of the fourth day, temperature 104; pulse 150 and thready. On the morning of the fifth day, the temperature was $105 \frac{1}{2}$; features pinched; respiration 36 , very restless. These symptoms continued until the child died in the afternoon from septic poison.

Case 3.-Nov. 5th, I was called by Dr. Ernest Yeager to intubate the larynx of Clarence M., æt. 2 years and 8 months. Considerable delay was occasioned in reaching the child which I found uncon- 